
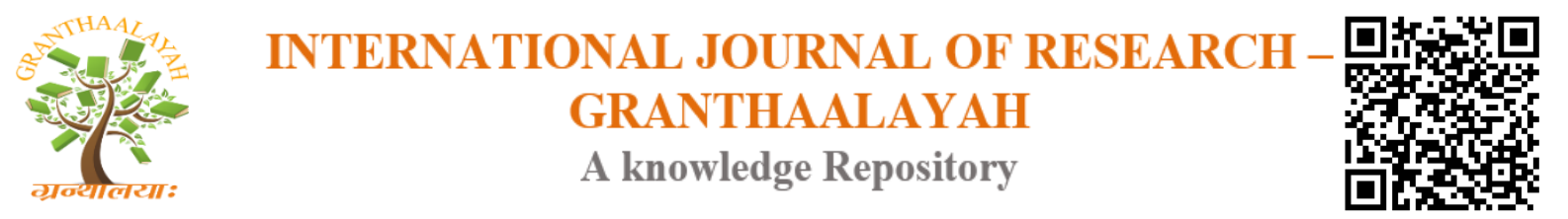

Science

\title{
A NEW APPROACH TO FIND THE INITIAL BASIC FEASIBLE SOLUTION OF A TRANSPORTATION PROBLEM
}

\author{
Ravi Kumar R ${ }^{* 1}$, Radha Gupta ${ }^{2}$, Karthiyayini $\mathrm{O}^{3}$ \\ ${ }^{* 1,3}$ Department of Science and Humanities, PESIT-Bangalore South Campus, Karnataka, India \\ ${ }^{2}$ Department of Mathematics, Dayandanda Sagar Collage of Engineering, Karnataka, India
}

\begin{abstract}
Transportation problem (TP) in operations research is a widely used optimization technique to study the problems concerned with transporting goods from production places to sale points. The TP may have one or more objectives such as minimization of transportation cost, minimization of distance with respect to time, and so on. There is a systematic method to solve such problems. For this, we find the Initial Basic Feasible Solution (IBFS) to the given problem. North West corner method, least cost method, Vogel's approximation method are the standard methods one uses to find the IBFS. In recent years, there are several other methods are proposed to solve such problems. In this paper, we propose a new technique named as Direct Sum Method (DSM) and its effectiveness is compared with the standard methods. The result shows that it is easy to compute and near to the optimum solution of the problem.
\end{abstract}

Keywords: Transportation Problem; Initial Basic Feasible Solution; Direct Sum Method.

Cite This Article: Ravi Kumar R, Radha Gupta, and Karthiyayini O. (2018). "A NEW APPROACH TO FIND THE INITIAL BASIC FEASIBLE SOLUTION OF A TRANSPORTATION PROBLEM." International Journal of Research - Granthaalayah, 6(5), 321-325. https://doi.org/10.29121/granthaalayah.v6.i5.2018.1457.

\section{Introduction}

Transportation Problem (TP) is a special type of Linear Programming Problem which deals with the distribution of single commodity from various sources of supply to various destinations of demand in such a way that the total transportation cost is minimized. Transportation problem was first presented by F.L.Hitchcock [1], in his paper "The distribution of a product from several sources to numerous localities" in the year 1941. Later in the year 1947, T.C.Koopmans [2], presented his historic paper "Optimum utilization of the transportation system". These two papers are the milestones in the development of the various methods to solve a transportation problem. A transportation problem when expressed in terms of an LP model can also be solved by simplex method given by G B Danzig in the year 1951 but it involves a large number of variables and constraints, solving it using simplex methods take a long time. Several researchers have developed alternative methods for finding an initial basic feasible solution which takes costs into account. 
There are three well-known methods namely, north West Corner Method (NWCM), least cost Method (LCM), Vogel's Approximation Method (VAM) to find the Initial Basic Feasible Solution (IBFS) of a Transportation Problem. In the recent time, some new heuristic methods have been developed such as Maximum Difference Method (MDM), Extremum Difference Method (EDM), and Modified Vogel's Approximation Method (MVAM) and so on. In MDM Method, Smita Sood and Keerthi Jain have shown that their method is most of the time better than that of VAM [4]. In MVAM, Abdul Sattar Soomro et al. described that the results of MVAM and VAM are almost same optimal but better than NWCM and LCM [9]. M.A.Hakim, in his paper, proposed a method called Proposed Approximation Method (PAM) and shown that his method and VAM give the same result [10].

\section{Materials and Methods}

\subsection{Mathematical Representation of TP}

The following notations are used for the mathematical representation of a Transportation Problem. Let ' $i$ ' denote an origin point out of ' $m$ 'number of origins.

Let ' $j$ 'denotes a destination point out of ' $n$ ' number of destinations.

Let $a_{i}$ denotes the available number of units at' ${ }^{\prime}$.

Let $b_{j}$ denotes the required number of units at ' $j$ '.

Let $c_{i j}$ denotes the transportation cost of a unit from $i^{\text {th }}$ origin to $j^{\text {th }}$ destination.

Let $x_{i j}$ be the number of units to be transported from $i^{\text {th }}$ origin to $j^{\text {th }}$ destination.

Using these notations, the transportation problem can be put in the form mathematically as: finding a set of decision variables $x_{i j}^{\prime} s$, for $i=1,2, \ldots, m ; j=1,2, \ldots, n$, to minimize

$$
Z=\sum_{i=1}^{m} \sum_{j=1}^{n} c_{i j} x_{i j}
$$

Subject to the constraints

$$
\begin{gathered}
\sum_{j=1}^{n} x_{i j}=a_{i} ; i=1,2, \ldots, m ; \\
\sum_{i=1}^{m} x_{i j}=b_{j} ; j=1,2, \ldots, n \\
\boldsymbol{x}_{i j} \geq \mathbf{O} .
\end{gathered}
$$

The solution of a Transportation problem consists of two stages; namely i) finding an initial basic feasible solution and ii) optimal solution. A set of non-negative allocations $x_{i j} \geq 0$, which satisfy the row and column restriction is known as a feasible solution. A feasible solution is basic if the number of positive allocations is $m+n-1$. If the number of positive allocations is less than $m+n-1$, then it is called degenerate feasible solution. A feasible solution is called an optimal solution if it minimizes the total transportation cost. 
There are three standard methods namely, north West Corner Method (NWCM), Least cost Method (LCM), Vogel's Approximation Method (VAM) to find the Initial Basic Feasible Solution (IBFS) of a Transportation Problem. Two transportation algorithms, namely Stepping Stone Method and the MODI (modified distribution) Method have been developed for finding the optimal solution of a transportation problem [3].

The allocation rule followed in all the algorithms is the least of the supply and demand of the corresponding source and destination of the selected cell for allocation.

\subsection{Algorithms of Standard Initial Basic Feasible Solution Methods and Direct Sum Method (Proposed Method)}

\subsubsection{North-West Corner Method (NWCM)}

Step 1: Select the North-West corner cell of the transportation table and allocate the amount of transportation as the minimum of the supply and the demand.

Step 2: If the demand for the demand for the first cell is satisfied, then move horizontally to the next cell in the second column.

Step 3: If the supply for the first row is exhausted, then move down to the first cell in the second row.

Step 4: Continue the process until all the supply and demand are exhausted.

\subsubsection{Least Cost Method (LCM)}

Step 1: Choose the cell with minimum cost and allocate as much as possible as per the allocation rule. If such a cell is not unique, choose any one arbitrarily.

Step 2: Cross out the satisfied row or column. Consider the remaining part of the table and continue the process until all the supply and demand are satisfied.

\subsubsection{Vogel's Approximation Method (VAM)}

Step 1: Compute the 'penalty' of each row and column. Here penalty is defined as the difference between the least and the next to the least costs.

Step 2: Identify the row or column with largest penalty and assign to the least cost cell in that row or column. If there is a tie, choose one arbitrarily.

Step 3: Continue this process, until all the supply and demand are satisfied.

\subsubsection{Algorithm of Direct Sum Method (DSM) - Proposed Method}

Step 1: Compute the 'direct sum cost' of each row and each column. Here the direct sum cost is defined as the sum of the transportation cost of each origin to various destinations and vice versa. Step 2: Identify the row or column with the largest direct sum cost and assign the minimum of supply or demand to the least cost cell in that row or column. If there is a tie, choose any one arbitrarily.

Step 3: Continue this process until all the supply and demand are satisfied. 


\section{Results and Discussions}

Problem-1

Consider the following transportation cost matrix. (Cost in Rupees).

Table 1:

\begin{tabular}{|l|l|l|l|l|l|}
\hline \multirow{2}{*}{ Factories } & \multicolumn{3}{|l|}{ Warehouses } & \multirow{2}{*}{ Supply } \\
\cline { 2 - 5 } & W & $\mathbf{X}$ & $\mathbf{Y}$ & $\mathbf{Z}$ & \\
\hline A & 3 & 6 & 8 & 4 & 20 \\
\hline B & 6 & 1 & 2 & 5 & 28 \\
\hline C & 7 & 8 & 3 & 9 & 17 \\
\hline DEMAND & 15 & 19 & 13 & 18 & 65 \\
\hline
\end{tabular}

This is a balanced transportation problem.

Problem-2

Consider the following transportation cost matrix.

Table 2:

\begin{tabular}{|l|l|l|l|l|}
\hline \multirow{2}{*}{ Source } & \multicolumn{3}{|l|}{ Destination } & Supply \\
\cline { 2 - 5 } & $\mathbf{1}$ & $\mathbf{2}$ & $\mathbf{3}$ & \\
\hline $\mathbf{1}$ & 6 & 10 & 14 & 50 \\
\hline $\mathbf{2}$ & 12 & 19 & 21 & 50 \\
\hline $\mathbf{3}$ & 15 & 14 & 17 & 50 \\
\hline Demand & 30 & 40 & 55 & \\
\hline
\end{tabular}

This is an unbalanced transportation problem.

\section{Results}

The initial basic feasible solution of the above listed problems 1, 2 by various methods discussed in this paper are tabulated below.

Table 3:

\begin{tabular}{|l|l|l|}
\hline Methods & Problem 1 & Problem 2 \\
\hline NWCM & 273 & 1815 \\
\hline LCM & 231 & 1885 \\
\hline VAM & 204 & 1745 \\
\hline DSM $*$ & $\mathbf{2 0 0}$ & $\mathbf{1 7 2 0}$ \\
\hline
\end{tabular}

\section{Conclusions and Recommendations}

From the Table-3, it can be concluded that the solution by this proposed method (Direct Sum Method) gives a better feasible solution than the other three standard methods. Hence it can be used for further optimization of the solution.

\section{References}

[1] Hitchcock, F.L. (1941). “THE DISTRIBUTION OF A PRODUCT FROM SEVERAL SOURCES TO NUMEROUS LOCALITIES”, Journal of Mathematical Physics, 20, 224-230. 
[2] Koopmans, T.C.(1947).”OPTIMUM UTILIZATION OF THE TRANSPORTATION SYSTEM”. Proceeding of the international statistical conference, Washington.D.C.

[3] J.K. Sharma, Operations Research- Theory and Applications, 5th Edition, Macmillan Publishers India Ltd.

[4] Smita Sood and Keerti Jain (2015). "THE MAXIMUM DIFFERENCE METHOD TO FIND INITIAL BASIC FEASIBLE SOLUTION FOR TRANSPORTATION PROBLEM, Asian Journal of Management Sciences 03 (07); 08-11.

[5] H. A. Taha, (2004) "OPERATIONS RESEARCH- INTRODUCTION" (Prentice Hall of India (PVT), New Delhi.

[6] Kanti Swarup, P. K. Gupta and Man Mohan,(2004) “OPERATIONS RESEARCH”, Sultan Chand \& Sons, 12th Edition.

[7] N.Sujatha (2015), “AN ADVANCED METHOD FOR FINDING AN OPTIMAL SOLUTION OF TRANSPORTATION PROBLEM, International Journal of Mathematical Archive-6(1), 2015.

[8] Mohammad Kamrul Hasan (2012), "DIRECT METHODS FOR FINDING OPTIMAL SOLUTION OF A TRANSPORTATION PROBLEM ARE NOT ALWAYS RELIABLE, International Refereed Journal of Engineering and Science, Volume1, Issue 2 .pp. 46-52.

[9] Abdul Sattar Soomro, et.al, (2015) “MODIFIED VOGEL'S APPROXIMATION METHOD FOR SOLVING TRANSPORTATION PROBLEMS, Mathematical theory and modeling, Vol.5, No.4.

[10] M.A.Hakim (2012), AN ALTERNATIVE METHOD TO FIND INITIAL BASIC FEASIBLE SOLUTION OF A TRANSPORTATION PROBLEM, Annals of Pure and Applied Mathematics, Vol.1,No.2,203- 209.

*Corresponding author.

E-mail address: ravikumarindur@gmail.com 